Article - Engineering, Technology and Techniques

\title{
X-ray Microtomography to Quantify Morphological Sandstones Properties
}

\author{
Luiz Fernando Pires ${ }^{1^{\star}}$ \\ https://orcid.org/0000-0001-5073-5900 \\ Mário Sérgio de Melo ${ }^{2}$ \\ https://orcid.org/0000-0002-6075-0650 \\ Jaqueline Aparecida Ribaski Borges ${ }^{1}$ \\ https://orcid.org/0000-0003-2609-9398 \\ Richard John Heck ${ }^{3}$ \\ https://orcid.org/0000-0003-4613-439X \\ Paulo Cesar Facin ${ }^{1}$ \\ https:// orcid.org/0000-0002-9822-8200
}

\begin{abstract}
1State University of Ponta Grossa, Department of Physics, Laboratory of Physics Applied to Soils and Environmental Sciences, Ponta Grossa, PR, Brazil; ${ }^{2}$ State University of Ponta Grossa, Department of Geosciences, Ponta Grossa, PR, Brazil; 3University of Guelph, School of Environmental Sciences, Guelph, ON, Canada.
\end{abstract}

Received: 2018.03.18; Accepted: 2019.05.19.

*Correspondence: Ifpires@uepg.br; luizfpires@gmail.com; Tel.: +55-42-32203043

\section{HIGHLIGHTS}

- Coarser sandstones presented higher porosities.

- Fine sandstones had larger number of pores.

- Genetic factors affected the size and shape of pores.

- 3D images with voxel size of $60^{3} \mu \mathrm{m}^{3}$ were evaluated.

\begin{abstract}
The sandstones of the Furnas Formation in the State of Paraná, south of Brazil, are located in regions with great importance due to the natural heritage found in the rocky forms and associated flora and fauna. This paper presents a detailed analysis of the internal structure of diverse sandstones of the Furnas Formation. X-ray microtomography allowed 3D characterization of the number, pore size and shape distributions of the sandstones. Images with voxel size of $60^{3} \mu \mathrm{m}^{3}$ were utilized to evaluate the sandstone's
\end{abstract}


macroporosity. The main results obtained indicate that higher macroporosities were observed in coarser and some types of silicified sandstones. In general, fine sandstones were characterized by the largest number of pores. As a general conclusion the size and shape distribution of pores seem to have a variable relation with genetic factors as grain size and cement (siliceous and/or ferruginous).

Keywords: image analysis; porous system; sandstone structure; 3D analysis; micromorphology.

\section{INTRODUCTION}

Since the development of the x-ray computed tomography (CT) in the early seventies of the last century [1], many applications of this technique have been found in different research domains. CT have been applied with great success in the geosciences, soil science, paleontology, materials science, medicine, plant science, and so on [2-8]. The technique is based on the interaction of radiation with material being analyzed [9]. The rotational and translational sample movements, in relation to the $x$-ray source and detector, provide projected images, through which, information about the internal structures of the samples analyzed are obtained [4].

The combination of the x-ray CT data and computer programs specifically written for image analysis, permits a 3D characterization of the porous system of complex materials such as sandstones [10-12]. CT is an interesting technique that can be utilized for nondestructive evaluations of micropores and macropores. Sandstones can be characterized in terms of the pore's shape, number, distribution, volume, surface area and connectivity by means of x-ray CT [13].

The analysis of the sandstone's macroporosity is crucial due to its role in the movement of water and gases in this kind of rock [12]. From the environmental point of view, the presence of macropores is also important, because toxic substances can infiltrate quickly through sandstones and reach the groundwater effecting its quality [14]. Therefore, a study of the number of macropores, as well as their size and distribution, shapes and connectivity, is crucial for a better characterization of sandstones.

The sandstones of the Furnas Formation represent an important protection for diverse micro-ecosystems, and are located in a region with rising demand for subterranean water for human consumption. These sandstones are also located in regions with several State parks, which were created to protect the natural heritage found in the rock forms and associated flora and fauna [15]. Therefore, the sandstones from the Furnas Formation are of considerable social, environmental and cultural importance.

It is important to emphasize that the literature concerning studies about the 3D x-ray CT characterization of the Furnas Formation sandstones is nonexistent. Taking this into consideration, the aim of this study is to evaluate the macroporous system of Brazilian sandstones from the Furnas Formation via x-ray CT. In order to achieve this objective, 3D analysis of the pore size, shape distributions and morphological parameters was performed.

\section{MATERIAL AND METHODS}

The Furnas Formation (Paleozoic of the Paraná Sedimentary Basin, southern Brazil) contains mainly fine to coarse quartz sandstones cemented by kaolinite and illite [15-16]. This formation is an important regional aquifer considered as a karst, where the corrosion of the kaolinite cement by intergranular solutions promotes the releasing of quartz grains and thus the arenisation of the sandstone, which becomes easily eroded, favoring the development of underground pores [17].

The sandstone samples were collected in the surface of the outcropping area of the Furnas Formation in the Paraná State, near the cities of Castro $\left(24^{\circ} 47^{\prime} \mathrm{S} ; 50^{\circ} 00 \mathrm{~W}\right)$, Tibagi 
(24 $\left.30^{\circ} \mathrm{S} ; 50^{\circ} 24 \mathrm{~W}\right)$ and Piraí do Sul $\left(24^{\circ} 28^{\prime} \mathrm{S}\right.$; $\left.49^{\circ} 53 \mathrm{~W}\right)$, and they represent rocks of different types and weathering stages (Table 1).

The sandstone samples were scanned with a "GE Medical $\mu$ CT EVSMS-8" system (EVS Corp., Toronto, ON). The CT system is composed by a 2D flat detector and a fixed conical $\mathrm{x}$-ray beam. The voltage and current applied to the x-ray tube were $120 \mathrm{kV}$ and $155 \mu \mathrm{A}$, respectively. A copper filter ( $0.5 \mathrm{~mm}$ thick) was placed at the output of the beam for the attenuation of the low-frequency $\mathrm{x}$-ray photons.

Regions of interest (ROI) were selected for reconstruction at $0.06^{3} \mathrm{~mm}^{3}$ voxel size, using the GEHC MicroView software, in the 3D images (Table 2) [18]. Three samples (replications) were studied for each type of sandstone collected. The processes of reconstruction, filtering and segmentation of the images were performed according to the protocol adopted by the research group of the Laboratory of Soil Image of the University of Guelph, CA [19]. After image reconstruction a 3D Gaussian filter was utilized to reduce image noises [18].

Segmentation was performed based on the grayscale histograms of each image. In order to eliminate the mixed voxels, which may cause the histogram peaks to widen, the relatively pure voxels (which present low variance in relation to their neighbors) were selected using the pure voxel extraction plugin developed specifically for this purpose [19]. In this plugin the measurement of the neighboring voxels average $(n=124)$, the comparison of this average with the central voxel value and the calculation of the standard deviation $(\sigma)$ is made. When $\sigma<0.1$, the voxels are classified as having low variability (homogeneous regions), which means elements of similar composition in the samples [14].

Table 1. Description of the undisturbed Brazilian sandstones from the Furnas Formation.

\begin{tabular}{|c|c|c|}
\hline Sample & Provenance & Description \\
\hline FU-02A1 & PR-190 (Piraí do Sul) & $\begin{array}{l}\text { Typical fine to medium cross-stratificated } \\
\text { sandstone }\end{array}$ \\
\hline FU-02A2 & PR-190 (Piraí do Sul) & $\begin{array}{l}\text { Typical fine to coarse cross-stratificated } \\
\text { sandstone }\end{array}$ \\
\hline FU-02C & PR-190 (Piraí do Sul) & Typical fine sandstone \\
\hline FU-10D & PR-340 (Castro-Tibagi) & Fine micaceous planar-stratificated sandstone \\
\hline FU-18B & Guartelá State Park & Silicified sandstone along vertical fracture \\
\hline FU-20A & Guartelá State Park & Ferruginized sandstone along horizontal fracture \\
\hline FU-25A1 & Guartelá State Park & Coarse sandstone in surface ruiniform relief \\
\hline FU-25A2 & Guartelá State Park & $\begin{array}{l}\text { Silicified coarse sandstone in surface ruiniform } \\
\text { relief }\end{array}$ \\
\hline FU-27A & Guartelá State Park & Silicified sandstone in vertical rock surface \\
\hline FU-27B & Guartelá State Park & Silicified sandstone in horizontal rock surface \\
\hline
\end{tabular}

The number, volume, location ( $x, y, z$ coordinates), surface area (SA) of pores divided by the total sample volume and main axes (major, intermediate and minor) of each detected pores were obtained from the reconstructed 3D images. The three main axes were utilized to classify the pores in terms of shape by using the Zingg classification system [20]. Thus, the sandstone pores were classified as Equant (EQ), Prolate (PR), Oblate (OB) and Triaxial (TR). Pore connectivity was determined by calculating the Euler number [21]. Highly connected structures present small and negative values of this number.

The following equations were used to obtain the macroporosity (Ma): 


$$
\begin{gathered}
V_{p}=N_{\text {voxels }}(v S)^{3}, \\
V_{t}=\sum V_{p}, \\
\mathrm{Ma}=\frac{\mathrm{V}_{\mathrm{p}}}{\mathrm{V}_{\mathrm{t}}} .
\end{gathered}
$$

where $\mathrm{N}_{\text {voxels }}$ corresponds to the number of voxels of $\mathrm{V}$, $\mathrm{vS}$ is the voxel size, $\mathrm{V}_{\mathrm{p}}$ and $\mathrm{V}_{t}$ are the volume of pores and the total image volume [14].

The number of pores (NP) was calculated taking into consideration the total number of disconnected macropores inside the total image volume. For Ma and NP distribution analyses, the macropores were classified at different size intervals: $0.002-0.01 ; 0.01-0.1$; $0.1-1 ; 1-10 ;>10 \mathrm{~mm}^{3}$. All the pore analyses were carried out for pores larger than 8 voxels [19].

Other parameters to access the complexity of the sandstone porous system were also measured. The fractal dimension (FD), which is an indicator utilized to measure and compare the roughness of a surface; and the degree of anisotropy (DA), which gives the preferred orientation of pores, were determined by using the Bone $\mathrm{J}$ plugin [22-24].

The statistical analysis was carried out using Past software [25]. Averages were calculated for each physical parameter studied and used to obtain the mean and standard error. Analyses of correlation were performed between each pair of variables for the entire set of data. The correlation coefficients $(R)$ were determined using the Pearson's test.

\section{RESULTS AND DISCUSSION}

Figure 1 illustrates the 2D and 3D segmented images after cubic sub-volume extraction. These images represent one of the three sample sandstone volumes reconstructed (Table 2). The sample choice was based on the comparison of its macroporosity to the average Ma $(n=3)$. Samples with Ma close to its average were selected.
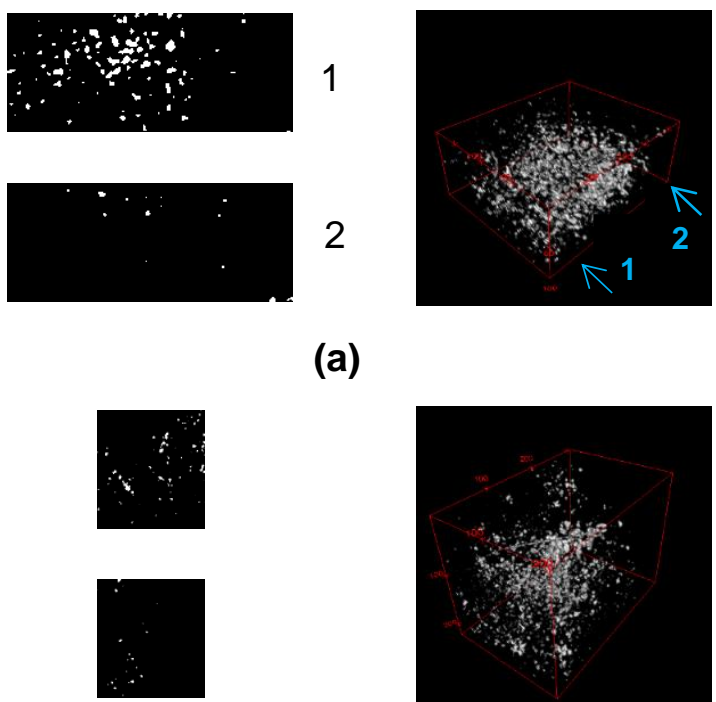

(a)

2

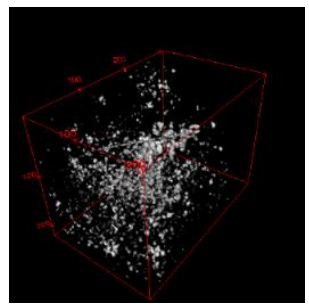

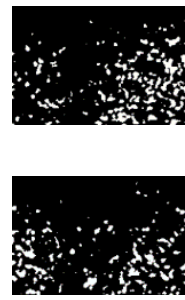
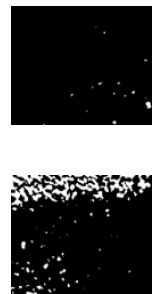

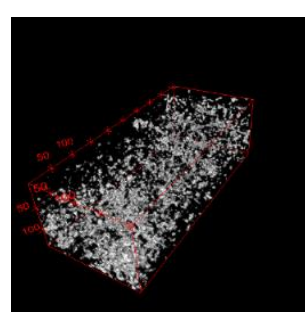

(b)

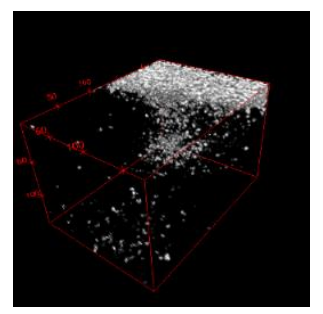

(d) 

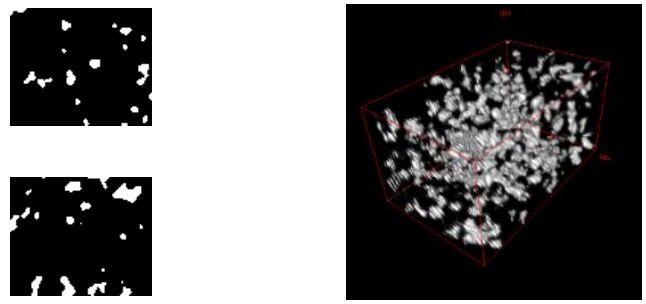

(e)
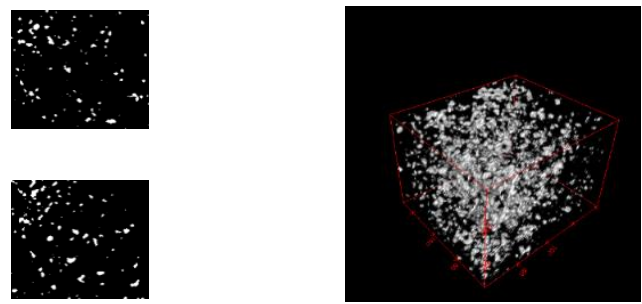

(g)
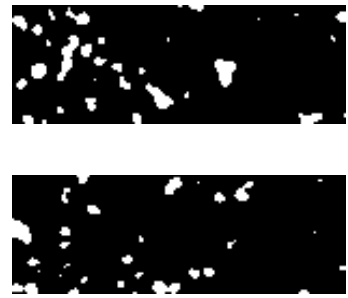

(i)

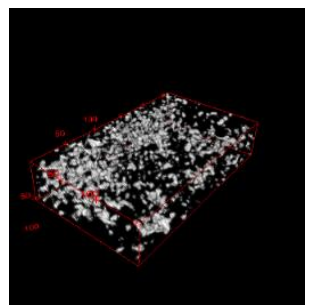

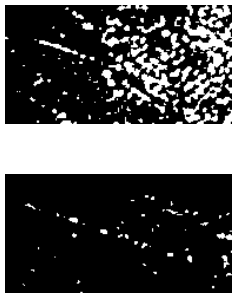

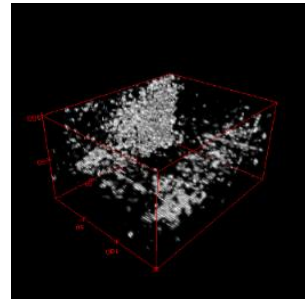

(f)
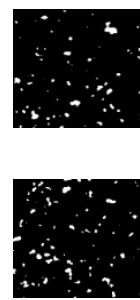

(h)

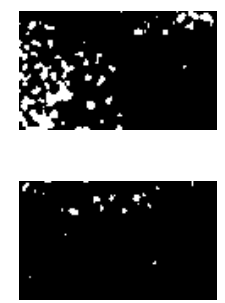

(j)

Figure 1. 2D and 3D CT segmented images of the Furnas Formation sandstones studied. Pores are showed in white. The blue arrows indicate the position of the sample sections selected for the $2 \mathrm{D}$ image analysis. (a) FU-02A1 sandstone; (b) FU-02A2 sandstone; (c) FU-02C sandstone; (d) FU10D sandstone; (e) FU-18B sandstone; (f) FU-20A sandstone; (g) FU-25A1 sandstone; (h) FU-25A2 sandstone; (i) FU-27A sandstone; (j) FU-27B sandstone.

The 3D images give an idea about the distribution of pores inside the sandstones and the 2D images about the shape and distribution of pores in two different positions (next to the borders) of them. Qualitative analysis of the segmented images revealed that some of the sandstones presented a more isotropic distribution of pores (FU-02A2, FU-18B, FU$25 \mathrm{~A} 1$ and FU25A2) than others (Figures $1 \mathrm{~b}, 1 \mathrm{e}, 1 \mathrm{~g}$ and $1 \mathrm{~h}$ ). The 2D images selected in positions close to the borders of the samples highlight this finding. Some sandstones were also characterized by concentrations of pores in specific regions of the sample (e.g. FU-10D and FU-20A), which indicate a structure composed by pores smaller (voxel size $<0.06^{3} \mathrm{~mm}^{3}$ ) than the resolution achieved [12,14]. 
Table 2. Volume of the Brazilian sandstone samples studied.

\begin{tabular}{cccc}
\hline & & $\mathbf{V}\left(\mathbf{m m}^{\mathbf{3}}\right)$ & \\
\cline { 2 - 4 } Sample & $\mathbf{S 1}$ & $\mathbf{S 2}$ & $\mathbf{S 3}$ \\
\hline FU-02A1 & 647 & 666 & 898 \\
FU-02A2 & 2601 & 2838 & 3005 \\
FU-02C & 4252 & 4946 & 4946 \\
FU-10D & 5011 & 1276 & 1345 \\
FU-18B & 487 & 480 & 229 \\
FU-20A & 574 & 690 & 640 \\
FU-25A1 & 953 & 979 & 1063 \\
FU-25A2 & 399 & 431 & 1004 \\
FU-27A & 389 & 490 & 458 \\
FU-27B & 458 & 548 & 501 \\
\hline
\end{tabular}

The highest and the lowest Ma values were noticed for FU-18B and FU-02C, respectively. The latter is classified as a typical fine sandstone and the former as a silicified sandstone from a vertical fracture $[15,17]$. The following sequence was observed regarding Ma: FU-27A > FU-25A2 > FU-25A1 > FU-10D > FU-02A2 > FU-20A > FU-02A1 > FU-27B (Figure 2a). In general, coarse sandstones were characterized by the largest Ma values. The smallest values were observed for fine sandstones and located along horizontal fracture or rock surface. For these sandstone types are expected small values of Ma due to their nature.

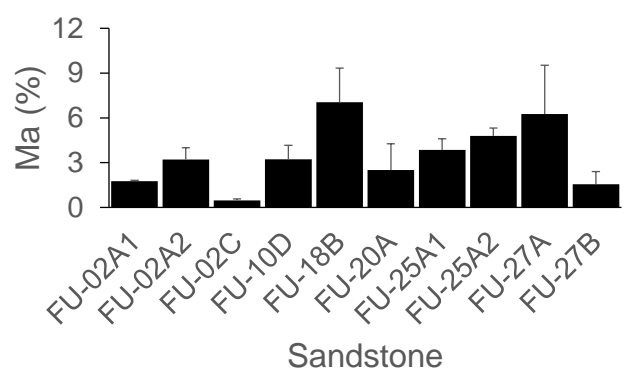

(a)

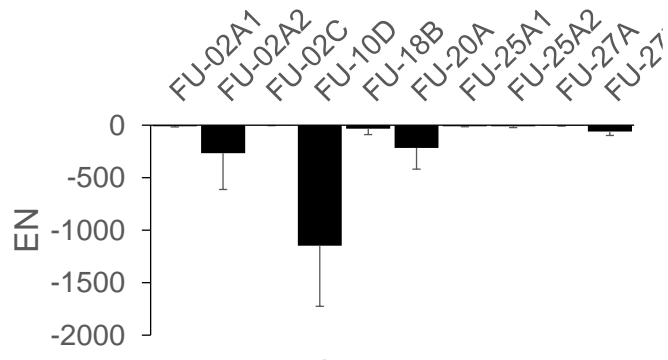

Sandstone

(c)

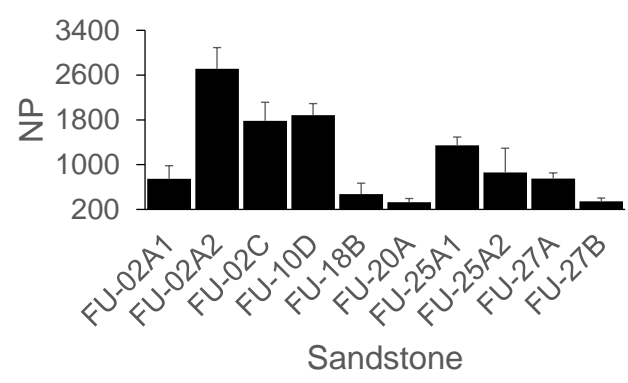

(b)

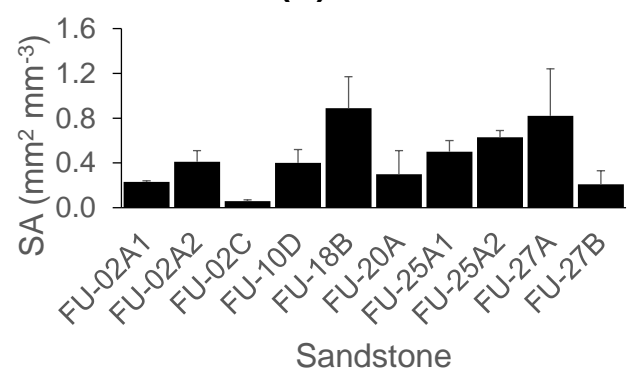

(d) 


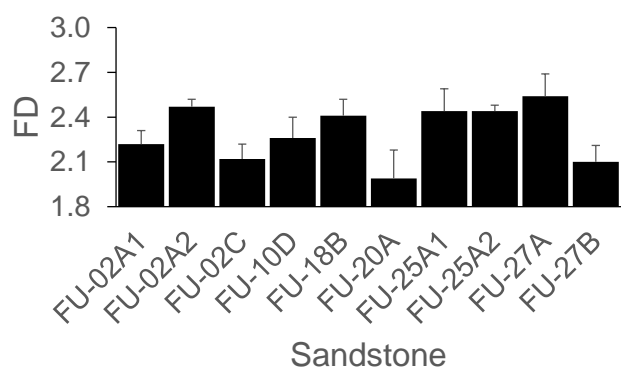

(e)

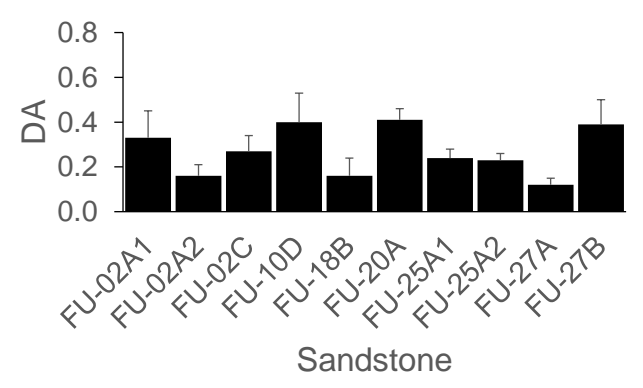

(f)

Figure 2. (a) Macroporosity (Ma); (b) Number of pores (NP); (c) Euler number (EN); (d) Surface area per volume (SA); (e) Fractal dimension (FD); (f) Degree of anisotropy (DA) for the different sandstone samples $(n=3)$ of the Furnas Formation studied.

In terms of NP, the highest and the lowest values were measured for FU-02A2 and FU$20 \mathrm{~A}$, respectively (Figure $2 \mathrm{~b}$ ). This result means that the latter is characterized by the presence of larger pores in relation to the former, based on Ma results. The following sequence was observed regarding NP: FU-10D > FU-02C > FU-25A1 > FU-25A2 > FU-27A > FU-02A1 > FU-18B > FU-27B. In general, fine sandstones were identified as those with the largest amount of resolvable pores, usually composed by pores of small sizes as compared to coarse sandstones.

Regarding the pore size distribution (Figure 3), FU-10D and FU-20A had similarities. The largest contributions to NP ( $\approx 66 \%$ : FU-10D; $\approx 73 \%$ : FU-20A) and Ma ( $\approx 66 \%$ : FU-10D; $\approx 49 \%$ : FU-20A) were found in the following pore size ranges $0.002-0.01 \mathrm{~mm}^{3}$ and $>10 \mathrm{~mm}^{3}$. These sandstones were characterized by concentrations of pores in specific regions of the samples (Figures 1d and 1f), which resulted in a better porous system connectivity for them (Figure 2c). However, it is important to highlight that the values of EN measured, in general, indicate low connected structures, which are associated with fragmented macropore networks [26-28].

For Ma, FU18-B and FU-27B were characterized by more homogeneous distribution of pore sizes between the volume intervals of 0.01 to $>10 \mathrm{~mm}^{3}$ and 0.002 to $10 \mathrm{~mm}^{3}$, respectively. FU-02A1 ( $\approx 50 \%)$ and $\mathrm{FU}-02 \mathrm{C}(\approx 61 \%)$ presented the maximum proportion of macropores for the volume of 0.01 to $0.1 \mathrm{~mm}^{3}$. These two sandstones were classified as

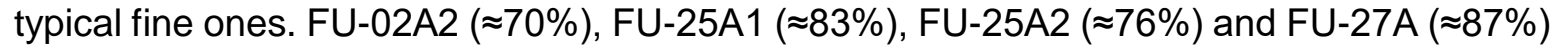
had maximum proportions in the pore volume intervals of 0.01 to 0.1 and 0.1 to $1 \mathrm{~mm}^{3}$, respectively. These four sandstones also showed similarities in terms of NP for these volume intervals and three of them presented coarse structures and intermediate values of $\mathrm{Ma}$ (Figure 2a and Figure 3).

For NP, pore volumes $<0.01 \mathrm{~mm}^{3}$ were the most frequent for FU-02A1 $(\approx 66 \%)$, FU-02C ( $\approx 68 \%), \mathrm{FU}-10 \mathrm{D}(\approx 66 \%), \mathrm{FU}-20 \mathrm{~A}(\approx 73 \%)$ and FU-27B ( $\approx 73 \%)$ (Figure 3). These sandstones were also identified as having structures composed by pores smaller (analysis not showed in this work) than the resolution achieved (Figure 1). In general, sandstones presenting almost the same concentrations of pores $<0.01 \mathrm{~mm}^{3}$ were characterized as having the smallest SA values, which means similarities in pore morphology and surface texturing (Figure 2d) [29-30].

Regarding the influence of the shape of pores in Ma (Figure 4), TR shaped pores were the most common. The following sequence was observed for TR: FU-18B ( $55 \%)>$ FU-27A $(\approx 51 \%)>$ FU-20A $(\approx 49 \%)>$ FU-02A $1(\approx 48 \%)>$ FU-02A2 $(\approx 47 \%)>$ FU-25A1 $(\approx 46 \%)>$ FU$10 \mathrm{D}(\approx 45 \%)>$ FU-25A2 ( $243 \%)>$ FU-27B $(\approx 35 \%)>$ FU-02C ( $\approx 33 \%)$. In general, the highest proportion of TR shaped pores was found for sandstones with the largest Ma (Figure 2a). These pores are also known as laminar due to their blade-like shape and a large amount of them was associated with small SA values (Figure 2c) [28]. 


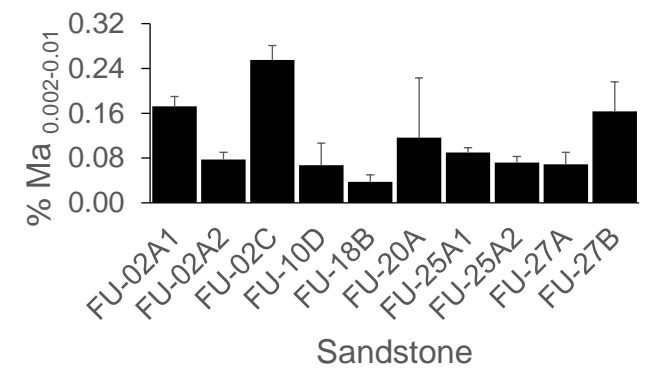

(a)

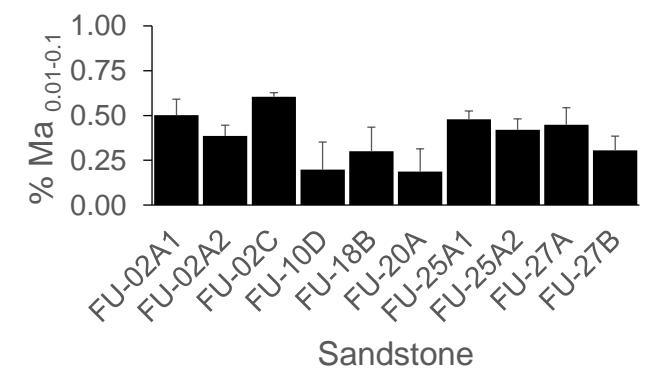

(c)

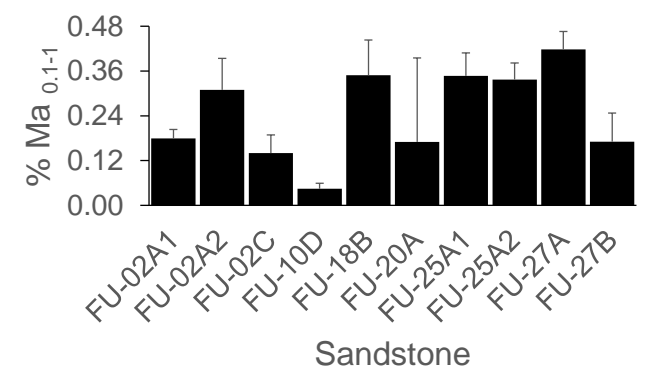

(e)

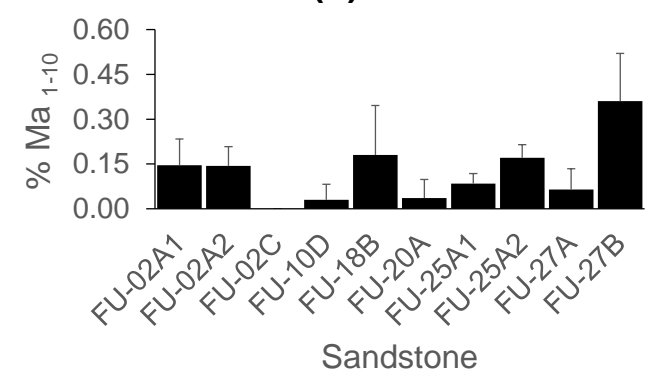

(g)

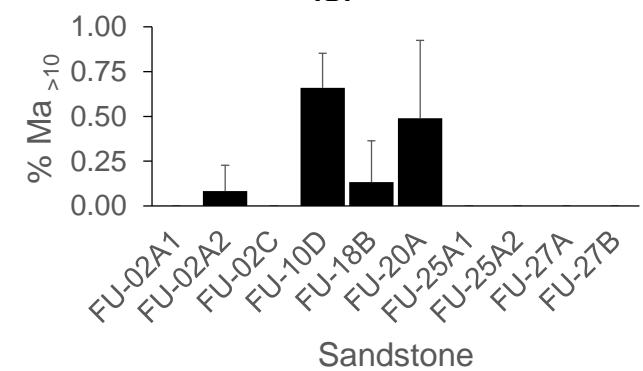

(i)

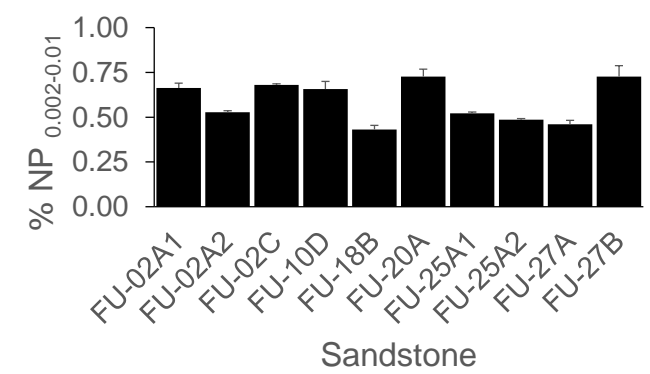

(b)

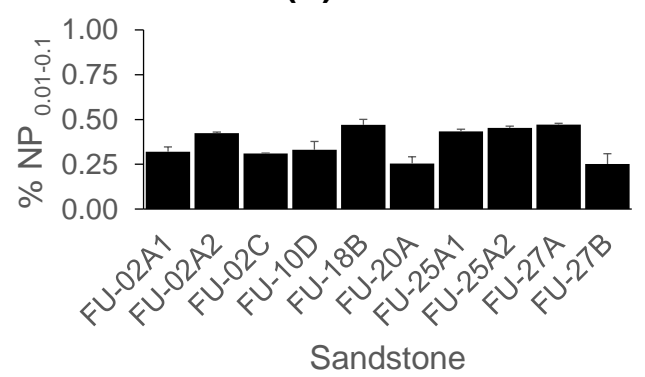

(d)

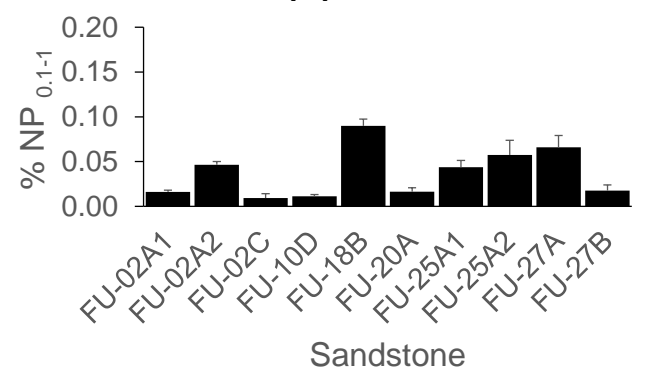

(f)

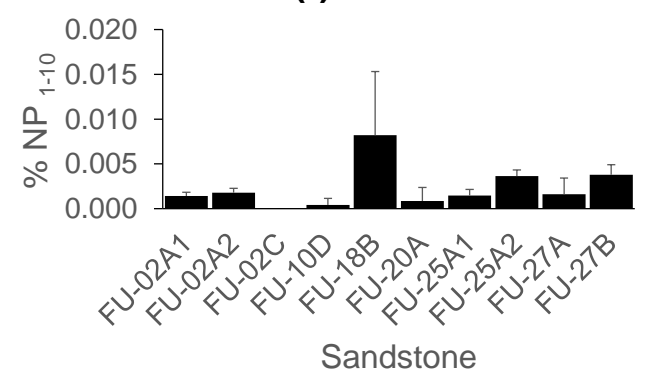

(h)

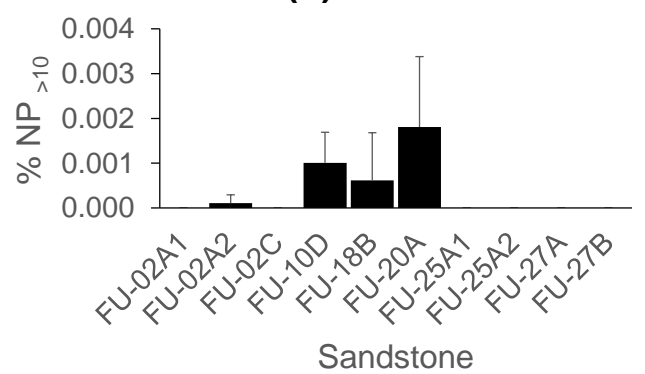

(j)

Figure 3. Distribution of macroporosity (Ma) and number of pores (NP) in terms of volume (V) of pore intervals for the Furnas Formation sandstones studied. The Ma and NP were obtained 
considering the total macroporosity and total number of pores. $(\mathbf{a}, \mathbf{b}) \quad 0.002-0.01 \mathrm{~mm}^{3} ;(\mathbf{c}, \mathbf{d}) 0.01-0.1$ $\mathrm{mm}^{3} ;(\mathbf{e}, \mathbf{f})$ 0.1-1 mm $;(\mathbf{g}, \mathbf{h}) 1-10 \mathrm{~mm}^{3} ;(\mathbf{i}, \mathbf{j})>10 \mathrm{~mm}^{3}$.

The other types of pores showed large proportions of EQ (spheroidal) and PR (channel) shaped pores, which are characterized as having cuboid-like (PR) and cube-like (EQ) shapes. The following sequence for $\mathrm{Ma}$ was observed for these two shapes: FU-02C $(\approx 55 \%)>$ FU-27B $(\approx 49 \%)>$ FU-20A $(\approx 49 \%)>$ FU-10D $(\approx 44 \%)>$ FU-25A2 ( $243 \%)>$ FU-

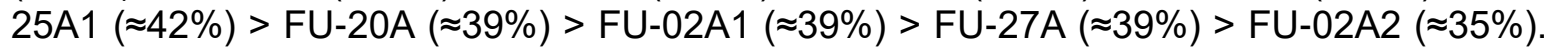
As pointed out before, FU-02C, FU-27B and FU-20A sandstones were characterized by structures composed of pores smaller than the resolution achieved and concentrations of pores in specific regions of the samples (Figure 1).

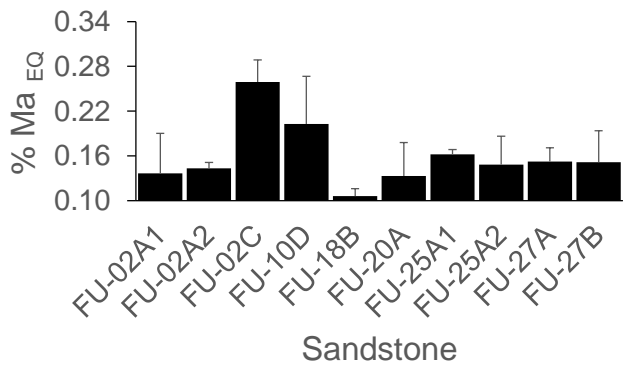

(a)

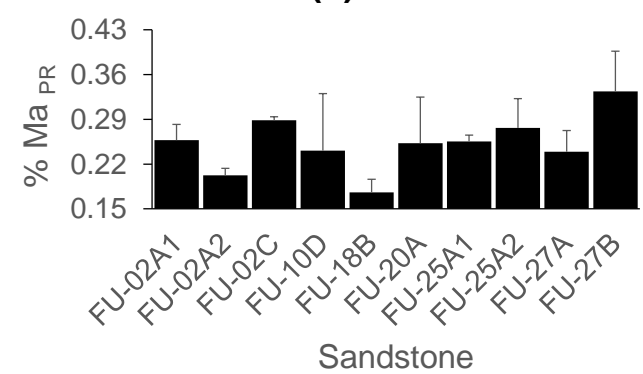

(c)

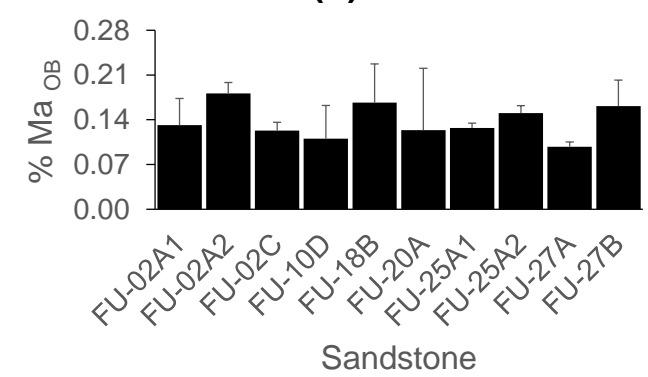

(e)

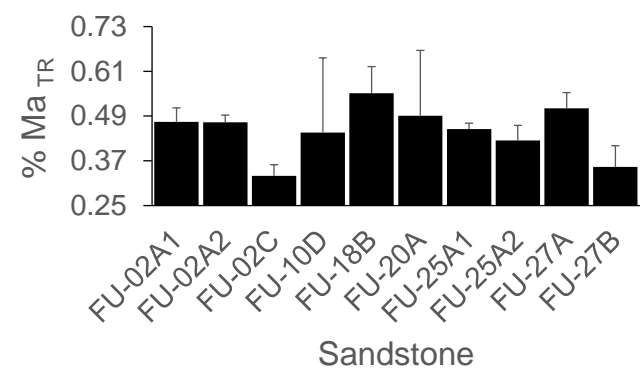

(g)

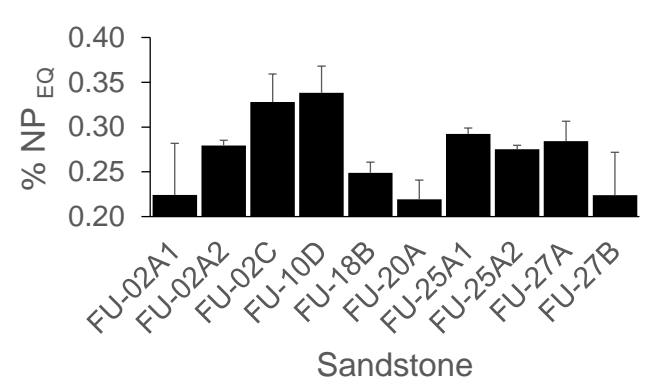

(b)

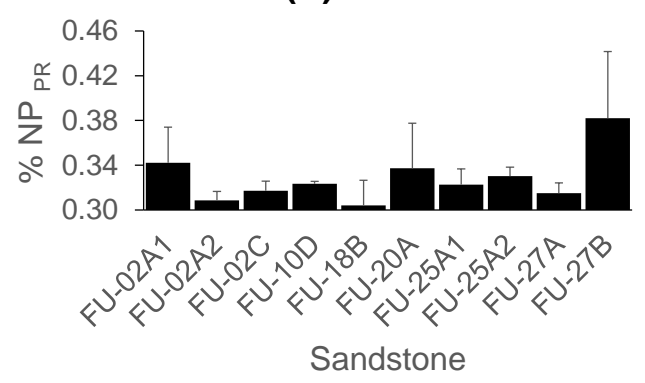

(d)

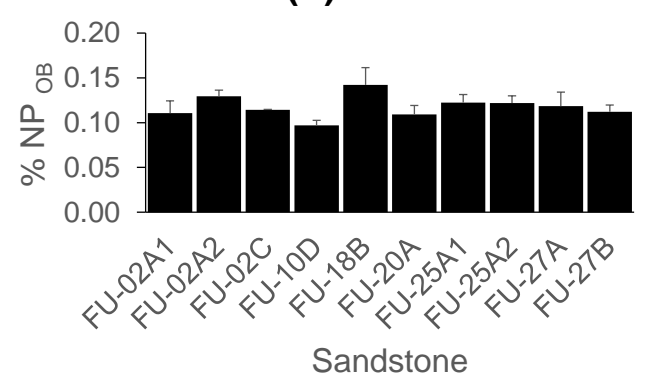

(f)

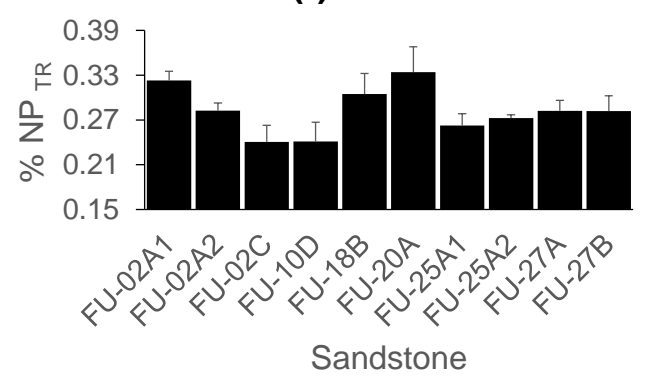

(h)

Figure 4. Distribution of macroporosity (Ma) and number of pores (NP) in terms of the shape of pores for the Furnas Formation sandstones studied. The Ma and NP contributions were obtained 
considering the total macroporosity and total number of pores. $(\mathbf{a}, \mathbf{b})$ Equant $(E Q)$ shaped pores; $(\mathbf{c}, \mathbf{d})$ Prolate (PR) shaped pores; (e,f) Oblate (OB) shaped pores; (g,h) Triaxial (TR) shaped pores.

In terms of NP, the smallest amount was noticed for OB shaped pores (Figure 4). However, in most of the cases the largest amount was found for PR shaped pores. In general, it was observed similarities in the tendencies of Ma and NP regarding the different shape of pores. Correlation analyses between NP and Ma were carried out to highlight these tendencies. High positive correlation coefficients were observed for all the pore shapes studied ( $R=0.99$ : $p<0.001$ - EQ; $R=0.96$ : $p<0.001$ - $P R ; R=0.94: p<0.001$ - OB; $R=0.85$ : $p<0.01-T R)$. Therefore, the largest the number of pores is the largest the macroporosity measured.

Regarding the fractal dimension, in general the sandstones with the largest Ma were also those characterized by the largest FD (Figures $2 a$ and $2 e$ ). Coarse sandstones had more complex pore structures as indicated by the large FD, which indicates rough pore surfaces [31,32]. The analysis of correlation between FD and Ma showed high positive correlations between these two parameters (Table 3).

Table 3. Pearson correlations between each pair of variables.

\begin{tabular}{ccccccc}
\hline & FD & DA & EN & SA & Ma & NP \\
\hline FD & 1 & $-0.853^{* *}$ & 0.119 & $0.767^{* *}$ & $0.748^{* *}$ & 0.291 \\
DA & $-0.853^{* *}$ & 1 & -0.441 & $-0.684^{*}$ & $-0.669^{*}$ & -0.225 \\
EN & 0.119 & -0.441 & 1 & 0.105 & 0.082 & -0.418 \\
SA & $0.767^{\star *}$ & $-0.684^{*}$ & 0.105 & 1 & $0.999^{* * *}$ & -0.226 \\
Ma & $0.748^{* *}$ & $-0.669^{*}$ & 0.082 & $0.999^{* * *}$ & 1 & -0.225 \\
NP & 0.291 & -0.225 & -0.418 & -0.226 & -0.225 & 1 \\
\hline
\end{tabular}

Significant at ${ }^{*} \mathrm{p}<0.05,{ }^{* *} \mathrm{p}<0.01,{ }^{* * *} \mathrm{p}<0.001$; FD: Fractal dimension; DA: Degree of anisotropy; EN:

Euler number; SA: Surface area; Ma: Macroporosity; NP: Number of pores

The results of DA give an idea about the isotropy of the porous system (Figure 2f). Small values of DA (close to 0 ) represent an isotropic porous system, while values close to 1 an anisotropic porous system [32]. Sandstones with concentrations of pores in specific regions (FU-02A1, FU-10D, FU-20A and FU-27B) were characterized as more anisotropic, as expected (Figures 1a, 1d, 1f and 1j). In general, coarse sandstones presented more isotropic porous structures in comparison to the fine ones. As coarse sandstones had large Ma values (Figure 2a), a negative high correlation was observed between Ma and DA (Table 3).

The correlation test showed significant correlations among some sandstone's morphological characteristics (Table 3). There were significant negative correlations between FD and DA, DA and SA and DA and Ma. For the sandstones studied, more complex pore structures are related to more homogeneous distribution (isotropic) of pores (FD $\times D A$ ), which was expected considering Ma and NP results (Figures $2 a$ and $2 b$ ) $[33,34]$. The same result was observed in terms of SA. On the other hand, there were positive correlations between FD and SA, FD and $\mathrm{Ma}$ and $\mathrm{Ma}$ and SA. Coarse sandstones were characterized by the largest Ma and FD and, consequently, SA (Figures 2a and 2d). In general, the more homogeneous the distribution of pores (Figure 1), the large their surface exposed to gases and solutes (>SA).

\section{CONCLUSION}

Results show that, in general, silicified and coarse sandstones were characterized by the largest macroporosity, while fine sandstones by the smallest. In terms of number of pores, the fine sandstones presented the highest amount of them. 
Poor connectivity was observed for all the sandstones considering the resolvable pores analyzed. The best connectivity was found in the fine micaceous planar-stratificated sandstone, which was characterized by a great concentration of pores in specific regions of the sample studied.

In terms of the surface area, in general, the sandstones with the most homogeneous distribution of pores were also identified as those with the largest values of SA. For the fractal dimension, the coarse sandstones had more complex porous systems and, consequently, higher surface roughness of pores. For the anisotropy, the concentration of pores in specific regions of the samples indicated more anisotropic porous systems.

Regarding the pore size distribution, there is no a clear relation between Ma and the nature of the sandstones. In general, the fine sandstones presented the highest contribution to Ma from pores with volumes of 0.01 to $0.1 \mathrm{~mm}^{3}$. Silicified sandstones were characterized by more homogenous distributions of pores, considering all the volume intervals studied. In terms of NP, in general the highest contribution was due to pore volumes of 0.002 to 0.01 $\mathrm{mm}^{3}$. Silicified sandstones were characterized by the highest contribution of pores with volumes of 0.002 and $0.1 \mathrm{~mm}^{3}$.

In terms of the shape of pores, the highest contribution to Ma was observed for triaxial (laminar) shaped pores. This result was found for all the sandstones studied. Regarding NP, in general the highest contribution was identified for equant and prolate shaped pores.

As a general conclusion, the size and shape distribution analyses of the sandstones porous system seem to have a variable relation with genetic factors of the rock as grain size and cement (siliceous and/or ferruginous). The same was observed for the analysis of fractal dimension, degree of anisotropy and connectivity. Porosity is a major factor controlling underground erosion and the karst system development in the outcropping area of the Furnas Formation. The comprehension of the relations between rock genetic factors, porosity and underground voids development is an urgent need for the environmental management of groundwater storage and exploitation, karst relief evolution, geoenvironmental hazards and geological heritage. Additional studies on the development of the porosity of the sandstones of the Furnas Formation, like presented in this work, can bring essential subsidies for the management of this important regional rock unit; mainly due to the importance of macropores to the infiltration and redistribution of solutes.

Funding: This research was funded by CNPq ("Conselho Nacional de Desenvolvimento Científico e Tecnológico"), grant number 303726/2015-6 and CAPES ("Coordenação de Aperfeiçoamento de Pessoal de Nível Superior"), grant number 88881.119578/2016-01.

Conflicts of Interest: The authors declare no conflict of interest.

\section{REFERENCES}

1. Hounsfield, G.N. Computerized transverse axial scanning (tomography): I. Description of system. Brit J Radiol 1973, 46, 1016-1022.

2. Salvo, L.; Cloetens, P.; Maire, E.; Zabler, S.; Blandin, J.J.; Buffière, J.Y.; Ludwig, W.; Boller, E.; Bellet, D.; Josserond, C. X-ray micro-tomography an attractive characterisation technique in materials science. Nucl Instrum Meth B 2003, 200, 273-286.

3. Marinho, D.A.; Reis, V.M.; Vilas-Boas, J.P.; Alves, F.B.; Machado, L.; Rouboa, Al.; Silva, A.J. Design of a three-dimensional hand/forearm model to apply computational fluid dynamics. Braz Arch Biol Technol 2010, 53, 437-442.

4. Pires, L.F.; Borges, J.A.R.; Bacchi, O.O.S.; Reichardt, K. Twenty-five years of computed tomography in soil physics: A literature review of the Brazilian contribution. Soil Till Res 2010, 110, 197-210.

5. Mooney, S.J.; Pridmore, T.P.; Helliwell, J.; Bennett, M.J. Developing X-ray Computed Tomography to non-invasively image 3-D root systems architecture in soil. Plant Soil 2011, 352, 122.

6. Teles, A.P.; Lima, I.; Lopes, R.T. Rock porosity quantification by dual-energy X-ray computed microtomography. Micron 2016, 83, 72-78. 
7. Rowe, T.B.; Luo, Z-X.; Ketcham, R.A.; Maisano, J.A.; Colbert, M.W. X-ray computed tomography datasets for forensic analysis of vertebrate fossils. Sci Data 2016, 3, 160040.

8. Cnudde, V.; Boone, M.N. High-resolution X-ray computed tomography in geosciences: A review of the current technology and applications. Earth-Sci Rev 2013, 123, 1-17.

9. Kaplan, I. Nuclear Physics, 2nd ed.; Addison-Wesley: Massachusetts, USA, 1977.

10. Appoloni, C.R.; Fernandes, C.P.; Rodrigues, C.R.O. X-ray microtomography study of a sandstone reservoir rock. Nucl Instrum Meth A 2007, 580, 629-632.

11. Moreira, A.C.; Appoloni, C.R.; Mantovani, I.F.; Fernandes, J.S.; Marques, L.C.; Nagata, R.; Fernandes, C.P. Effects of manual threshold setting on image analysis results of a sandstone sample structural characterization by X-ray microtomography. Appl Radiat Isotopes 2012, 70, 937-941.

12. Cid, H.E.; Carrasco-Núñez, G.; Manea, V.C. Improved method for effective rock microporosity estimation using X-ray microtomography. Micron 2017, 97, 11-21.

13. Pires, L.F.; Borges, J.A.R.; Rosa, J.A.; Cooper, M.; Heck, R.J.; Sabrina, P.; Roque, W.L. Soil structure changes induced by tillage systems. Soil Till Res 2017, 165, 66-79.

14. Passoni, S.; Pires, L.F.; Heck, R.; Rosa, J.A. Three dimensional characterization of soil macroporosity by X-ray microtomography. Rev Bras Ciência do Solo 2015, 39, 448-457.

15. Melo, M.S.; Giannini, P.C.F. Sandstone dissolution landforms in the Furnas Formation, southern Brazil. Earth Surf Process Landf 2007, 32, 2149-2164.

16. De Ros, L.F. Heterogeneous generation and evolution of diagenetic quartzarenites in the Silurian-Devonian Furnas Formation of the Paraná Basin, southern Brazil. Sediment Geol. 1998, 116, 99-128.

17. Melo, M.S.; Guimarães, G.B.; Chinelatto, A.L.; Giannini, P.C.F.; Pontes, H.S.; Chinelatto, A.S.A.; Atencio, D. Kaolinite, illite and quartz dissolution in the karstification of Paleozoic sandstones of the Furnas Formation, Paraná Basin, Southern Brazil. J South Am Earth Sci 2015, 63, 20-35.

18. GE Healthcare. GE Healthcare eXplore Locus User Guide, 2005.

19. Jefferies, D.A.; Heck, R.J.; Thevathasan, N.V.; Gordon, A.M. Characterizing soil surface structure in a temperate tree-based intercropping system using X-ray computed tomography. Agrofo Syst 2014, 88, 645-656.

20. Zingg, T. Beitrag zur Schotteranalyse. Schweiz Mineral Petrogr Mitt 1935, 15, 39-140.

21. Toriwaki, J.; Yonekura, T. Euler number and connectivity indexes of a three dimensional digital picture. Forma 2002, 17, 183-209.

22. Doube, M.; Kłosowski, M.M.; Arganda-Carreras, I.; Cordelières, F.P.; Dougherty, R.P.; Jackson, J.S.; Schmid, B.; Hutchinson, J.R.; Shefelbine, S.J. BoneJ: Free and extensible bone image analysis in ImageJ. Bone 2010, 47, 1076-1079.

23. Fazzalari, N.L.; Parkinson, I.H. Fractal dimension and architecture of trabecular bone. J Pathol 1996, 178, 100-105.

24. Harrigan, T.P.; Mann, R.W. Characterization of microstructural anisotropy in orthotropic materials using a second rank tensor. J Mater Sci 1984, 19, 761-767.

25. Hammer, $\varnothing$.; Harper, D.A.T.; Ryan, P.D. PAST: Paleontological statistics software package for education and data analysis. Palaeont Elect 2001, 4, 1-9.

26. Chappard, D.; Legrand, E.; Pascaretti, C.; Basl, M.F.; Audran, M. Comparison of eight histomorphometric methods for measuring trabecular bone architecture by image analysis on histological sections. Microsc Res Tech 1999, 45, 303-312.

27. Vogel, H-J.; Weller, U.; Schlüter, S. Quantification of soil structure based on Minkowski functions. Comput Geosci 2010, 36, 1236-1245.

28. Schmitt, M.; Halisch, M.; Müller, C.; Fernandes, C.P. Classification and quantification of pore shapes in sandstone reservoir rocks with 3-D X-ray micro-computed tomography. Solid Earth 2016, 7, 285-300.

29. Lowell, S.; Shields, J.E.; Thomas, M.A.; Thommes, M. Characterization of porous solids and powders: surface area, pore size and density. 1st ed.; Kluwer Academic Publishes: Dordrecht, Germany, 2006.

30. Hillel, D. Environmental Soil Physics. 1st ed. Academic Press: New York, USA, 1998.

31. Muñoz, F.J.; Martínez, F.S.J.; Caniego, F.J. Fractal Parameters of Pore Space from CT Images of Soils Under Contrasting Management Practices. Fractals 2014, 22, 1440011. 
32. Ferreira, T.R.; Pires, L.F.; Wildenschild, D.; Brinatti, A.M.; Borges, J.A.R.; Auler, A.C.; dos Reis, A.M. Lime application effects on soil aggregate properties: Use of the mean weight diameter and synchrotron-based X-ray $\mu \mathrm{CT}$ techniques. Geoderma 2019 338, 585-596.

33. Tseng, C.L.; Alves, M.C.; Crestana, S. Quantifying physical and structural soil properties using X-ray microtomography. Geoderma 2018, 318, 78-87.

34. Pires, L.F.; Mooney, S.J.; Auler, A.C.; Atkinson, B.; Sturrock, C.J. X-ray microtomography to evaluate the efficacy of paraffin wax coating for soil bulk density evaluation. Geoderma 2019 337, 935-939.

(C) 9018 by the authors. Submitted for possible open access publication
under the terms and conditions of the Creative Commons Attribution (CC
BY NC) license (https://creativecommons.org/licenses/by-nc/4.0/). 